\title{
Guidelines For The Final Year Project Assessment In Engineering
}

\author{
Elena Valderrama, Mercè Rullán, Fermín Sánchez, Jordi Pons, Claudi Mans, Francesc Giné, Laureà \\ Jiménez, Enric Peig \\ Elena.Valderrama@uab.cat, Mercedes.Rullan@uab.cat, fermin@ac.upc.edu, Jordi.Pons@uab.cat, cmans@ub.edu, \\ sisco@diei.udl.cat, Laureano.Jimenez@urv.cat, enric.peig@upf.edu
}

\begin{abstract}
This paper presents an efficient and objective procedure for the outcome-based assessment of engineering final year projects (FYP). The procedure, consisting of 6 steps, can easily be customized for different engineering curricula. A User Guide has been developed to help institutions create their own FYP assessment system. The guide includes the assessment procedure and aids for its implementation. Particularly, a set of FYP-oriented observable descriptors for Tuning outcomes was defined. The end-products of the proposed assessment procedure are a set of assessment reports that the evaluator agent/s must fulfil per milestone, marking the level reached by the student at every descriptor (0: unacceptable, 1: minimum acceptable, 2: good, 3: excellent). These marks are then gathered together in an overall assessment sheet showing, for every learning outcome, the evolution along the assessment milestones of the level reached by the student at any descriptor. This sheet is a very powerful tool for setting the final mark. All assessment agents use the same list of descriptors and the same levels of acquisition, thus improving the consistency, traceability and global quality of the assessment process.
\end{abstract}

Index Terms - Assessment, Assessment reports, Final year project, Learning outcomes.

\section{INTRODUCTION}

Engineering curricula include the development and assessment of a final year project (FYP). This FYP represents the culmination of the student learning process, where he/she must put into use their previously learned engineering and personal skills. The FYP is a complex event, and its assessment has a major influence on decisions regarding the student's readiness to graduate.

In our country (Spain), FYP students are assessed in most schools on the basis of a final written report of the work done plus a public defense before an academic jury composed of several experienced professors. Unfortunately, this approach presents serious drawbacks:
- Assessment has to mandatory shift to an outcome-based approach to come into line with education and accreditation processes [2],[3],[7].

- Assessment via a unique final milestone clashes directly with the formative purpose of assessment.

- Assessment is highly dependent on the subjective criteria of academic jury.

In December 2007, the $\mathrm{AQU}^{1}$ and the MICINN ${ }^{2}$ launched a program for the development of a User Guide for the outcome-based assessment of engineering FYP. Six universities $^{3}$ from Catalonia took on the task of developing this User Guide.

A survey of the results of that project is reported here.

\section{THE USER GUIDE}

The User Guide developed is aimed at the academic authorities that have to define Syllabuses for FYP, and provides them with a strategy for making an assessment of the same. It contains a series of guidelines to help each Faculty or College to produce its own procedure for assessing FYP.

The User Guide proposes a process based on 6 stages that Faculties and Colleges must follow to define their own procedure of assessing FYP:

1. Definition of (i) the learning outcomes associated with the FYP and (ii) a set of objective descriptors for each of them;

2. Definition of (i) the moments (milestones) of assessment, (ii) the specific assessment actions that must be performed at each milestone and (iii) the agents that will carry out the assessment;

3. Assignation of descriptors to each assessment action;

4. Definition of the levels of compliance with each descriptor, clearly and objectively establishing the level of competence that the student must demonstrate that he/she possesses;

1 Agency for the Quality of the Catalan University System.

2 Spanish Ministry of Science and Innovation

3 Autonoma University of Barcelona (UAB), Technical University of Catalonia (UPC), University of Barcelona (UB), Lleida University (UdL),

Rovira i Virgili University (URV) and Pompeu Fabra University (UPF). 
Session M2J

5. Drafting of assessment reports that the assessment agents must complete and

6. Definition of the marking criteria to be used to assign the final mark for the FYP on the basis of the results reflected in the assessment report.

Figure 1 shows the described procedure in graphic form.

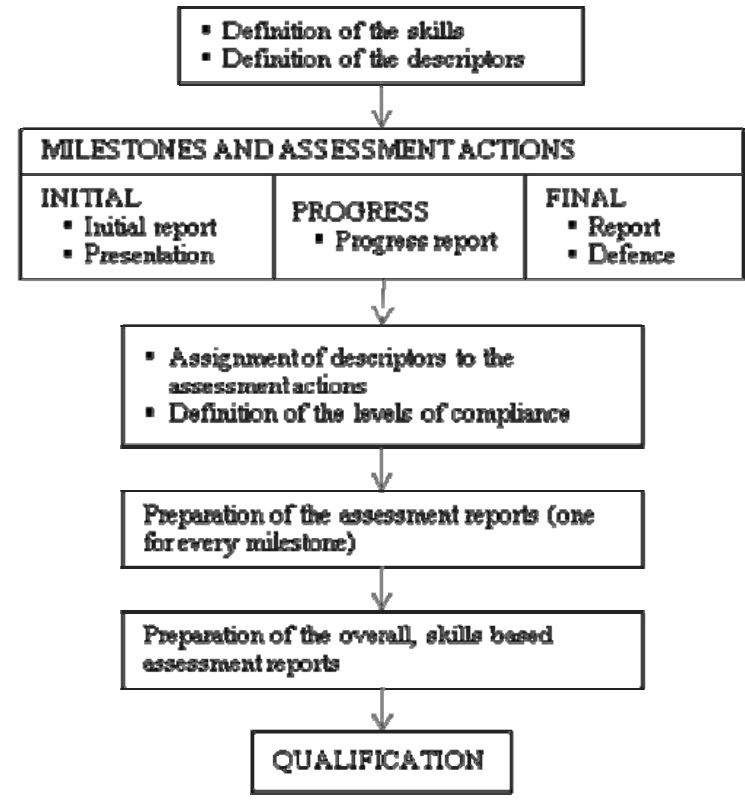

FIGURE 1

PROCEDURE PROPOSED FOR THE DEFINITION OF THE FYP ASSESSMENT PROCESS.

\section{Definition of skills and descriptors}

The first step in the process consists of establishing what skills the students must show they possess on completing their FYP. The specific (technical) skills are very different depending on the specific studies, but the transversal (generic) skills of any engineer are probably very similar, regardless of their speciality.

To assist with the definition of the transversal skills, a survey was prepared and conducted of a sample group of professors, who were asked to select, from a set of 28 transversal skills as defined by the Tuning project [4], the ones that they felt should be prioritized when assessing FYP. 135 valid responses were received, 108 from Spanish academics and 27 from the rest of the European Community. This text is too short to allow us space to show the final priority suggested for all the skills but, as an example, table 1 shows the 5 skills that received the highest scores. The full results of the survey can be found in [1].

In order to be able to evaluate these skills, there is a need to define a set of objective descriptors that make it possible to evaluate the level of acquisition of the skill by the student. For each skill, a file was created that (i) describes the skill from the point of view of the FYP, (ii) defines descriptors for its assessment, and (iii) establishes the level that students must

show they have acquired for each descriptor. The file suggests at which assessment milestone (see later) each descriptor should be assessed.

TABLE I

MOST VOTED SKILLS FOR THEIR ASSESSMENT WITHIN THE FYP

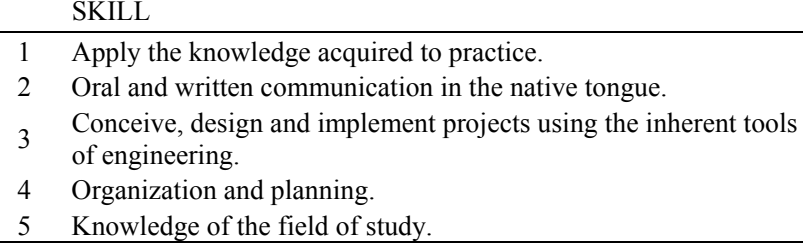

Both the issue of surveys of skills and the definition of descriptors are matters that have been dealt with on numerous occasions [5],[6], but what is new about this study is that it is centred on the assessment of skills in the context of FYP.

\section{Milestones, actions and assessment agents}

We propose the establishment of at least three moments or "milestones" for the assessment of FYP:

(i) A first assessment that must be made during the first few weeks of project, when the student has been working on their project for long enough to develop a clear approach to the work, to have analysed the state-of-the-art of the subject and its viability, and to have established a work plan; (ii) one (or several) milestones for monitoring the project in the long term, better in the second half of their development, when dysfunctions in the initial approach can be detected but when there is still time to make the necessary corrections and (iii) a final assessment milestone when the work is completed.

At each milestone, one or several assessment actions are proposed. The first milestone includes two assessment actions: (i) the presentation of an initial report and (ii) a presentation of this report to the student's colleagues and assessment agents. The intermediates milestone(s) includes a single action: the presentation of a project progress report and an eventual interview with the assessment agent if it is considered necessary. The final milestone continues the traditional method of presenting a final report of the work and its public presentation.

TABLE II

TIME SCALE, ACTIONS AND ASSESSMENT AGENT FOR EVERY MILESTONE

\begin{tabular}{|c|c|}
\hline $\begin{array}{l}\text { ACTIONS: } \\
\text { - Initial report } \\
\text { - Presentation of the report }\end{array}$ & $\begin{array}{l}\text { AGENTS: } \\
\text { - Tutor } \\
\text { - Colleagues } \\
\text { - Professor or external expert }\end{array}$ \\
\hline \multicolumn{2}{|c|}{ PROGRESS MILESTONE: In the second $1 / 3$} \\
\hline $\begin{array}{l}\text { ACTIONS: } \\
\text { - Progress report }\end{array}$ & $\begin{array}{l}\text { AGENTS: } \\
\text { - Tutor }\end{array}$ \\
\hline \multicolumn{2}{|c|}{ FINAL MILESTONE: At the end of the FYP } \\
\hline $\begin{array}{l}\text { ACTIONS: } \\
\text { - Report } \\
\text { - Public defence before tribunal }\end{array}$ & $\begin{array}{l}\text { AGENTS: } \\
\text { - Tribunal (inclusion of an external } \\
\text { expert recommended) }\end{array}$ \\
\hline
\end{tabular}




\section{Session M2J}

Finally, the agents that should evaluate each of the actions are proposed. We consider that the supervisor/tutor of the work should be involved in the assessment of all the actions. It would also be recommendable to make peer evaluation at the first milestone, and add the presence of external experts in the assessment of the monitoring and final milestones.

\section{Assignation of descriptors to the assessment actions}

Having reached this point, the descriptors defined for each skill have to be distributed among the assessment actions so that the evaluator knows what specific points need to be assessed at each moment. The skills files produced include a recommended assignation of the descriptors at each assessment milestone. Both the descriptors that appear in the skills files and their assignation to each specific milestone are suggestions to make things easier for the people in charge of centres. The final selection of descriptors and their assignation to milestones and assessment actions should be determined for each school.

It is important to underline the need for careful selection of the set of skills and descriptors to be assessed. We advise against trying to evaluate more than 10 or 15 descriptors in a single action, because this could lose sight of the student's work perspective.

Each qualification should define which skills and via which descriptors each action is to be assessed. The skills files [1] may be of assistance.

\section{$I V$. Level of compliance with the descriptors}

Finding out what descriptors have to be assessed is not enough: For the assessment to be objective and independent of the evaluator there is a need to accurately define the level of compliance that is demanded of the student in each.

Four levels of compliance are proposed for the descriptors: Level 1 corresponds to the minimum that the student must be able to demonstrate, and for a level below that (level 0) it is considered that the student does NOT comply with the descriptor. Level 2 is that which is considered adequate for the FYP. Level 3 represents an excellent level.

Table 3, shows an example of the definition of the four levels of compliance (level 0 is defined by exclusion) of the descriptors associated to the skill of "Organisation and planning".

\section{$V$. Assessment reports}

The assessment reports that must be completed by the assessment agents are constructed after assigning the descriptors to the assessment actions and defining the levels of demand. Two types of report are proposed: Assessment Reports organised by milestones, and the Overall Assessment Report, organized by skills.

The Assessment Reports constitute the final product of the assessment milestones; they contain the set of descriptors to be assessed, a column for the mark (from 0 to 3 ) and the levels of demand for each descriptor. These reports must be public and their result should be provided to the student as quickly as possible.
TABLE III

LEVEL OF COMPLIANCE WITH THE DESCRIPTORS FOR THE SKILL "ORGANISATION AND PLANNING"

DESCRIPTOR 1 : The student presents a diagram of the project plan

\begin{tabular}{l|l|l} 
LEVEL 1: Score 1 if.. & LEVEL 2: Score 2 if.. & LEVEL 3: Score 2 if..
\end{tabular}

A plan of the time The tasks, times and The level of detail by and resources required human and material which tasks, times and is presented, even if resources are perfectly resources are specified the level of detail is identified and planned is excellent

superficial

DESCRIPTOR 2 : The student is able to monitor the level of compliance with the initial plan, identifying and analysing the deviations detected

\begin{tabular}{l|l|l} 
LEVEL 1: Score 1 if.. & LEVEL 2: Score 2 if.. & LEVEL 3: Score 2 if..
\end{tabular}

The student is able at Identifies discrepancies Solutions proposed all times to identify from the established for any deviations are the state of each task plan and proposes very coherent and (behind schedule, actions to resolve them. guarantee, as much as ahead of time, on $\quad$ possible, compliance

time) with the project

DESCRIPTOR 3: The student analyses the level of final compliance with the initial plan, the causes of eventual deviations and the consequences of the same.

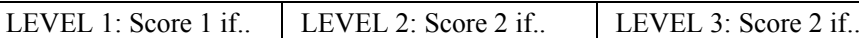
A plan of the time The tasks, times and and resources required human and material is presented, even if resources are perfectly the level of detail is superficial identified and planned The level of detail by which tasks, times and resources are specified is excellent

Thus, the assessment serves its educational role, by indicating to the student what they will be assessed on and telling them after each assessment action what their position is with respect to the expected learning objectives and what aspects they need to improve in order to reach them. Table 4 shows a (partial) example of the Assessment Report at the first milestone. The compliance levels, as defined in table 3 , should be included in columns levelled as 1,2 and 3 .

The results of these assessment actions are used to automatically complement the Overall Assessment Report. This report groups the set of assessments made, but now organised by skills, in such a way that it is easy to visualise the student's evolution over time. Table 5 shows an example of this report.

The overall assessment report is the one that makes it possible to qualify the student, in view not only of the final level of acquisition of the skills associated to the work, but also their evolution over time.

Working with a list of objective descriptors and objective criteria for marking, which are scaled on different levels, homogenises qualifications even when they originate from different assessment agents, increases the traceability of the results, and hence, improves the quality of the process of FYP assessing.

\section{Qualification}

Finally, the Faculty or College must define the criteria to be followed in order to provide the students with qualifications. These criteria must define minimums, allowing for a certain freedom in the analysis of the overall quality of the work done. 
TABLE IV

EXAMPLE OF THE ASSESSMENT REPORT CORRESPONDING TO THE INITIAL MILESTONE

\begin{tabular}{|c|c|c|c|c|}
\hline \multicolumn{2}{|l|}{ Action: Initial report } & \multirow[b]{2}{*}{1} & \multirow[b]{2}{*}{2} & \multirow[b]{2}{*}{3} \\
\hline Descriptors & $\begin{array}{c}\text { Points } \\
(0-3)\end{array}$ & & & \\
\hline $\begin{array}{l}\text { Identify the fundamental parts of the } \\
\text { project, drawing a diagram on a block } \\
\text { level that describes and displays the }\end{array}$ & 1 & $\begin{array}{l}\text { Score } 1 \\
\text { if ... }\end{array}$ & $\ldots$ & \\
\hline $\begin{array}{l}\text { Identify the knowledge implied in } \\
\text { resolving the project, both those } \\
\text { belonging to the discipline and from } \\
\text { outside of it }\end{array}$ & 2 & $\begin{array}{l}\text { Score } 1 \\
\text { if ... }\end{array}$ & & \\
\hline $\begin{array}{l}\text { Evaluate the relative importance of } \\
\text { each of the parts of the project of the } \\
\text { project and the knowledge implied. }\end{array}$ & 2 & $\begin{array}{l}\text { Score } 1 \\
\text { if ... }\end{array}$ & & \\
\hline Etc.... & $\ldots$ & $\ldots$ & & \\
\hline \multicolumn{2}{|l|}{ Action: Presentation } & & & \\
\hline Descriptors & $\begin{array}{r}\text { Points } \\
(0-3)\end{array}$ & & & \\
\hline $\begin{array}{l}\text { Shows empathy with the audience; } \\
\text { looks at the audience; uses the right } \\
\text { tone and volume of voice,... }\end{array}$ & 2 & $\begin{array}{l}\text { Score } 1 \\
\text { if ... }\end{array}$ & & \\
\hline \multicolumn{4}{|l|}{ Comments: } & \\
\hline Signed: (The assessment agent) & & & & \\
\hline
\end{tabular}

One of the outstanding aspects of the process described in this article is that, once the assessment procedure has been defined, it is very easy to automate the process. A web application can be made available in which the evaluators enter their qualifications at each milestones and both the overall report and the final qualification be automatically generated by following the criteria defined, thus avoiding human error and guaranteeing the transparency of the process.

\section{DISCUSSION}

There is a need to promote a change in the procedures for assessing students in the context of the new student-focused teaching-learning paradigm in all years, and especially in FYP.

The current model for assessing FYP, basically aimed to control if the student reaches the required level, based on the assessment of technical content and a highly dependent of the assessment agents, should give way for a model that highlights the training aspect of the assessment, that values skills ahead of mere knowledge and in which the assessment is as objective and retro-traceable as possible. The objective of the User Guide that has been produced is to help Faculties and Colleges to define procedures for assessing FYP that comply with these requisites.

The definition of objective descriptors and levels of compliance with them that are to be used by all of the agents
TABLE V

EXAMPLE OVERALL ASSESSMENT REPORT. M-1, M-2 AND M-3 CORRESPOND RESPECTIVELY TO THE INITIAL, PROGRESS AND FINAL MILESTONES

\section{OVERALL ASSESSMENT REPORT}

SKILL 1: Ability to conceive, design and implement projects using the inherent tools of Engineering

\begin{tabular}{|c|c|c|c|}
\hline Descriptors & $M-1$ & $M-2$ & $M-3$ \\
\hline $\begin{array}{l}\text { Choose the most adequate tools } \\
\text { and methodologies to analyse, } \\
\text { design and implement the project. }\end{array}$ & & 2 & \\
\hline $\begin{array}{l}\text { Analyse, design and implement } \\
\text { the project in accordance with the } \\
\text { most adequate methodologies. }\end{array}$ & & 2 & 2 \\
\hline $\begin{array}{l}\text { Find a solution to the proposed } \\
\text { project that can be carried out } \\
\text { considering the inherent resources } \\
\text { of Computer Engineering. }\end{array}$ & 1 & 2 & \\
\hline ... etc. & & & \\
\hline \multicolumn{4}{|l|}{ Comments: } \\
\hline \multicolumn{4}{|c|}{ SKILL 2: Capacity for analysis and synthesis. } \\
\hline Descriptors & $M-1$ & $M-2$ & $M-3$ \\
\hline $\begin{array}{l}\text { Identify the fundamental parts of } \\
\text { the project; drawing a diagram } \\
\text { than on a block level visually } \\
\text { describes the relationships } \\
\text { between them. }\end{array}$ & 1 & 3 & \\
\hline $\begin{array}{l}\text { Evaluate the results of the project, } \\
\text { comparing them with similar } \\
\text { results proceeding from sources } \\
\text {... etc. }\end{array}$ & & & 3 \\
\hline ... etc. & & & \\
\hline \multicolumn{4}{|l|}{ Comments: } \\
\hline SKILL 3: ... & & & \\
\hline
\end{tabular}

that intervene in the analysis of students helps increase the independence of the qualification from the different assessment agents, should give way for a model that highlights the training aspect of the assessment, that values skills ahead of mere knowledge and in which the assessment is as objective and retro-traceable as possible. The objective of the User Guide that has been produced is to help Faculties and Colleges to define procedures for assessing FYP that comply with these requisites.

The definition of objective descriptors and levels of compliance with them that are to be used by all of the agents that intervene in the analysis of students helps increase the independence of the qualification from the different assessment agents, and at the same time solves the problem of traceability. The question asked by students, "Why has the tribunal marked my work with a "C"?" is answered by the overall assessment report, which in turn is ratified by the assessment reports on each action, by the definition of the levels of compliance with the descriptors and by the actual definitions of the same. 
Similarly, the publication of assessment reports has a direct effect on the educational aspect of the assessment. Here it is important to highlight the importance of making the assessment model public and accessible both to professors and assessment agents and to students: Milestones, actions, skills, descriptors to be assessed for each action, level of expected achievement and the assessment reports, etc. The students must find out the results given by each of the evaluators as soon as possible so that these can guide the work that they have yet to do.

\section{CONCLUSIONS}

The User Guide that has been developed provides an efficient and objective mechanism for the assessment of FYP. It is a flexible instrument that each centre must personalise in accordance with their objectives. The Assessment Guide resulting from this personalisation will help increase the homogeneity of qualifications, the traceability of results, and the general quality of the process of assessing FYP.

\section{ACKNOWLEDGMENT}

One of the problems with working in teams is honouring the valuable input made by of all of the members without the list being seemingly never-ending. We have included six authors in the report, but there were many, many more:

Components of the AQU-MICINN project

Elena Valderrama (UAB), Jesús Bisbal (UPF), Julián Carrera (UAB), Francesc Castells (URV), Fernando Cores (UdL), Jordi García (UPC), Laureano Jiménez (URV), Claudi Mans (UB), Tomàs Margalef (UAB), Asunción Moreno (UPC), Enric Peig (UPF), Julio Pérez (UAB), Jordi Pons (UAB), Mercè Rullán (UAB), Fermín Sánchez (UPC), Gonzalo Seco (UAB), Joan Sorribes (UAB), Javier Tejero (UB), Ramón Vilanova (UAB).
Thank you to all of them.

\section{REFERENCES}

[1] AQU (Agència per a la qualitat del sistema universitari a Catalunya). Guia per a l'avaluació de competències en els Treballs Fi d'Estudis a les Enginyeries. 2009. In press.

[2] Complete Set Dublin Descriptors 2004. http://www.jointquality.org/. Last access, February 2009.

[3] NCES. Defining and Assessing Learning: Exploring Competency-Based Initiatives. 2002. Electronic version accessible at: http://nces.ed.gov/pubs2002/2002159.pdf Last access February 2009.

[4] Tuning Project. Una introducción a Tuning Educational Structures in Europe.. Electronic version accessible at: http://tuning.unideusto.org/tuningeu/images/stories/template/General_Bro chure_Spanish_version.pdf. Last access, February 2009.

[5] Sánchez F. et al. Competencias profesionales del Grado en Ingeniería Informática. JENUI 2008.

[6] Villa, A; Poblete, M. Aprendizaje basado en competencias. Ed Mensajero. Universidad de Deusto. 2007

[7] Voorthess, R. Measuring what matters: competency-based learning models. Higher Education. Jossey Bass. 2001

\section{AUTHOR INFORMATION}

Elena Valderrama, Autonoma University of Barcelona. Elena.Valderrama@uab.cat

Mercè Rullán, Autonoma University of Barcelona.

Mercedes.Rullan@uab.cat

Fermín Sánchez, Technical University of Catalonia. Fermin@ac.upc.edu

Jordi Pons, Autonoma University of Barcelona. Jordi.Pons@uab.cat

Claudi Mans, University of Barcelona.cmans@ub.edu

Francesc Giné, University of Lleida. sisco@diei.udl.cat

Laureà Jiménez, Rovira Virgili University.

Laureano.Jimenez@urv.cat

Enric Peig, Pompeu Fabra University. enric.peig@upf.edu 